\title{
Spermatic Cord Perforation
}

National Cancer Institute

\section{Source}

National Cancer Institute. Spermatic Cord Perforation. NCI Thesaurus. Code C78625.

An opening in the wall of the spermatic cord. 